\title{
ESOPHAGEAL BOLUS TRANSIT IN NEWBORN WITH GASTROESOPHAGEAL REFLUX
}

\author{
F. Cresi, S.A. Liguori, E. Locatelli, P. Di Nicola, A. Varalda, C. Martano, E. Bertino
}

Neonatal Care Unit, Department of Pediatrics, University of Torino, Torino, Italy

Background and aim: Gastroesophageal dismotility due to immaturity is primarily involved in the pathogenesis of gastroesophageal reflux (GER) in newborns. Impaired swallowing patterns could influence refluxes characteristics and esophageal acid exposure. Multichannel Intraluminal Impedance (MII) is a novel technique to evaluate GER, and it has been used to evaluate esophageal bolus transit in adults and children, but data on its use in newborns are scanty.

The aim of this study was to investigate the relation between esophageal motor disfunction and GER.

Methods: Esophageal bolus transit was evaluated in 16 term newborns aged 15-30 days, who underwent $24 \mathrm{~h}-\mathrm{pH} / \mathrm{MII}$ analysis for clinical suspect of GER disease. Eight patients had $\geq 5 \%$ time with esophageal $\mathrm{pH}<$ 4 (GER positive) and the other 8 patients had $<5 \%$ time with esophageal $\mathrm{pH}<4$ (GER negative). Bolus Head Advance Time (BHAT) and Total Bolus Transit Time (TBTT) were assessed on 3-hours intervals of MII recording.

Results: BHAT and TBTT were calculated on a total of 1056 swallowing events MII detected.

\begin{tabular}{|l|l|l|l|l||}
\hline & meal BHAT(s) & meal TBTT(s) & fasting BHAT(s) & fasting TBTT(s) \\
\hline GER negative & $0.45(0.16)$ & $1.10(0.18)$ & $2.71(0.44)$ & $4.46(0.43)$ \\
\hline GER positive & $0.65(0.35)$ & $1.56(0.58) *$ & $2.35(0.44)$ & $4.15(0.67)$ \\
\hline
\end{tabular}

[Table 1.Bolus Transit time analysis results.]

BHAT and TBTT observed during meal were shorter than in the fasting periods in both groups $(\mathrm{p}<0.001)$. During meal, TBTT, but not BHAT, was longer $(p=0.03)$ in the GER positive than in the GER negative group.

Conclusions: Our results support that esophageal motor disfunction contributes to the pathogenesis of GER in newborns, impairing esophageal clearance. 